\title{
The significance of surgery following concurrent chemoradiotherapy for locally advanced esophageal squamous cell carcinoma
}

\author{
Masanobu Nakajima, Hiroto Muroi, Maiko Kikuchi \\ First Department of Surgery, Dokkyo Medical University, Mibu, Shimotsuga-gun, Tochigi 321-0293, Japan \\ Correspondence to: Masanobu Nakajima, MD, PhD. First Department of Surgery, Dokkyo Medical University, 880 Kitakobayashi, Mibu, Shimotsuga- \\ gun, Tochigi 321-0293, Japan. Email: mnakajim@dokkyomed.ac.jp. \\ Provenance: This is an invited Editorial commissioned by the Section Editor Dr. Zhiheng Xu (State Key Laboratory of Respiratory Disease, \\ Guangzhou Institute of Respiratory Disease, Department of Intensive Care, The First Affiliated Hospital of Guangzhou Medical University, \\ Guangzhou, China). \\ Comment on: Barbetta A, Hsu M, Tan KS, et al. Definitive chemoradiotherapy versus neoadjuvant chemoradiotherapy followed by surgery for stage II \\ to III esophageal squamous cell carcinoma. J Thorac Cardiovasc Surg 2018;155:2710-21.e3.
}

Submitted Aug 31, 2018. Accepted for publication Sep 14, 2018.

doi: $10.21037 /$ jtd.2018.09.58

View this article at: http://dx.doi.org/10.21037/jtd.2018.09.58

Esophageal cancer is the sixth most common cause of cancer-related mortality worldwide because of its poor prognosis (1). Advanced esophageal cancer cannot be cured by a traditional monotherapy method; instead a multidisciplinary therapy is required. Many therapeutic strategies have been developed to date, and several controlled studies have been performed to ensure their efficacy.

In first decade of the 2000s, the results of the two randomized controlled trials that had compared the superiority of a neoadjuvant chemoradiotherapy (CRT) plus surgery, versus a definitive CRT had been published (2,3). These trials showed no benefit in patients who had received surgery. However, because of some qualitative problems, these trials have not been treated as an example of the best treatment practice.

The recently published Chemoradiotherapy for Esophageal Cancer Followed by a Surgery Study (CROSS), which was a prospective and randomized control study that compared the difference between surgery alone with neoadjuvant CRT followed by surgery for adenocarcinoma (AC), and squamous cell carcinoma (SCC) (4). This study is the largest study to date which had investigated neoadjuvant CRT in esophageal cancer ( 275 cases of AC, 84 cases of SCC). The CROSS had showed significant survival benefits for neoadjuvant CRT. The CROSS also showed a new standard of care for the management of locally advanced esophageal SCC: weekly carboplatin plus a paclitaxel combined with radiation of 41.1 Gy followed by surgery. Notably, the postoperative mortality rate was not increased in the trimodality group of the CROSS.

Although they were not randomized and controlled trials, several studies have shown the superiority of a planned surgery after the usage of a concurrent CRT over definitive CRT. Particularly for SCC, retrospective studies from Eastern countries have demonstrated that trimodality treatment is associated with better long-term survival rate $(5,6)$.

In this article, Barbetta et al. had introduced a Japanese study (JCOG 1406-A) (7). They described that this study showed a significantly improved progression-free survival rate and the overall survival rate for patients treated with a trimodality treatment over the definitive CRT. However, their description is erroneous. JCOG 1406-A study had utilized the stored data from the two previous prospective trials of patients with a locally advanced esophageal SCC [JCOG 9906 (8) and JCOG9907 (9)]. Although JCOG 9906 was just a phase II study of the definitive CRT for stage II/ III cancer, JCOG 9907 was a randomized trial which had compared postoperative adjuvant chemotherapy versus preoperative chemotherapy (not CRT).

In the present study, the authors retrospectively had 
compared the effect between a trimodality treatment versus the definitive CRT for a stage II and III SCC using a propensity score-matching approach. As a result, they demonstrated the superiority of a trimodality treatment in regards to the overall survival and disease-free survival chances. In the United States, where a definitive CRT is the most common treatment for the locally advanced esophageal SCC, despite national guidelines recommending a trimodality treatment for patients suitable for surgery, the significance of their work lies in their evaluations of the role of surgery with curative intent after CRT for a locally advanced esophageal SCC. The 5-year overall survival rate was $29 \%$ (95\% confidence interval, 18-49\%) for a definitive CRT and 45\% (95\% confidence interval, 33-62\%) for a trimodality treatment. This result is reasonable, and acceptable when it is compared with the past retrospective studies.

A remarkable point is that most patients in both the trimodality and definitive CRT groups had received the same doses of radiation therapy (50.4 Gy). In Japan, esophagectomy for residual or recurrent diseases after a definitive CRT (radiation dose of $>50 \mathrm{~Gy}$ ) is defined as "salvage surgery" by the Japanese Esophageal Society (10). Japanese "salvage surgery" for patients who have undergone a high-dosage of radiotherapy is considered to be a highly invasive surgery; in fact, it is associated with high postoperative mortality and morbidity rate (11). In the present study, the postoperative 30-day mortality rate was only $2 \%$ in the trimodality treatment group. This finding is important because most of the patients were treated with a radiation dose of $>50$ Gy. Ideally, the authors should reveal the details of their chemotherapy regimen, radiation field, and other parameters of their study. That aside, it is encouraging that the present study has demonstrated the efficacy and safety of a trimodality treatment, because a reliable preoperative tool with which to predict a pathological complete response has not yet been established. Interestingly, the prognosis of patients who have underwent the surgery was better than that of the patients who were treated with a definitive CRT, despite the higher reduction rate of the positron emission tomography in the standardized uptake value for the definitive CRT group than that of the trimodality group. This fact must support the significance of a surgery following CRT.

In conclusion, this study is meaningful, despite its limitations which are related to its retrospective design, as the authors have mentioned. A newly planned high-quality randomized controlled study is desired.

\section{Acknowledgements}

We thank Angela Morben, DVM, ELS, from Edanz Group (www.edanzediting.com/ac), for editing a draft of this manuscript.

\section{Footnote}

Conflicts of Interest: The authors have no conflicts of interest to declare.

\section{References}

1. Torre LA, Bray F, Siegel RL, et al. Global cancer statistics, 2012. CA Cancer J Clin 2015;65:87-108.

2. Stahl M, Stuschke M, Lehmann N, et al. Chemoradiation with and without surgery in patients with locally advanced squamous cell carcinoma of the esophagus. J Clin Oncol 2005;23:2310-7.

3. Bedenne L, Michel P, Bouché O, et al. Chemoradiation followed by surgery compared with chemoradiation alone in squamous cancer of the esophagus: FFCD 9102. J Clin Oncol 2007;25:1160-8.

4. van Hagen P, Hulshof MC, van Lanschot JJ, et al. Preoperative chemoradiotherapy for esophageal or junctional cancer. N Engl J Med 2012;366:2074-84.

5. Nomura M, Oze I, Kodaira T, et al. Comparison between surgery and definitive chemoradiotherapy for patients with resectable esophageal squamous cell carcinoma: a propensity score analysis. Int J Clin Oncol 2016;21:890-8.

6. Liu S, Qiu B, Luo G, et al. TNM staging matchedpair comparison of surgery after neoadjuvant chemoradiotherapy, surgery alone and definitive chemoradiotherapy for thoracic esophageal squamous cell carcinoma. J Cancer 2017;8:683-90.

7. Nomura M, Kato K, Ando N, et al. Comparison between neoadjuvant chemotherapy followed by surgery and definitive chemoradiotherapy for overall survival in patients with clinical Stage II/III esophageal squamous cell carcinoma (JCOG1406-A). Jpn J Clin Oncol 2017;47:480-6.

8. Kato K, Muro K, Minashi K, et al. Phase II study of chemoradiotherapy with 5 -fluorouracil and cisplatin for Stage II-III esophagealsquamous cell carcinoma: JCOG trial (JCOG 9906). Int J Radiat Oncol Biol Phys 2011;81:684-90.

9. Ando N, Kato $\mathrm{H}$, Igaki $\mathrm{H}$, et al. A randomized trial comparing postoperative adjuvant chemotherapy with cisplatin and 5-fluorouracil versus preoperative 
chemotherapy for localized advanced squamous cell carcinoma of the thoracic esophagus (JCOG9907). Ann Surg Oncol 2012;19:68-74.

10. Japan Esophageal Society. Japanese Classification of Esophageal Cancer, 11th Edition: part I. Esophagus 2017;14:1-36.

Cite this article as: Nakajima $\mathrm{M}$, Muroi $\mathrm{H}$, Kikuchi $\mathrm{M}$. The significance of surgery following concurrent chemoradiotherapy for locally advanced esophageal squamous cell carcinoma. J Thorac Dis 2018;10(Suppl 33):S3843-S3845. doi: 10.21037/ jtd.2018.09.58
11. Nakamura T, Hayashi K, Ota M, et al. Salvage surgery after definitive chemoradiotherapy for esophageal cancer. Esophagus 2005;2:123-8.

(English Language Editor: Jeremy Dean Chapnick, AME Publishing Company) 